\title{
O ESTÁGIO SUPERVISIONADO E SUA IMPORTÂNCIA NA FORMAÇÃO DE PROFESSORES NO CURSO DE PEDAGOGIA
}

\section{THE SUPERVISED INTERNSHIP AND ITS IMPORTANCE IN TEACHER TRAINING IN THE PEDAGOGY COURSE}

\author{
Ivanise Melo de Souza ${ }^{1}$ \\ Verônica Pereira da Silva ${ }^{2}$ \\ Ramony Maria Silva Reis Oliveira ${ }^{3}$
}

\section{RESUMO}

O Estágio Curricular Supervisionado desempenha um papel fundamental nos cursos de formação de professores possibilitando o acesso aos conhecimentos específicos ou da área de referência, conhecimentos pedagógicos apoiados em componentes curriculares, conhecimentos que são objetos de ensino e conhecimentos da prática profissional. Nesta perspectiva, este estudo teve como objetivo analisar a importância do Estágio Supervisionado na percepção dos acadêmicos do Curso de licenciatura em Pedagogia na Unimontes. Está estudo apresenta uma abordagem qualitativa, sendo utilizado o questionário como instrumento de coleta de dados. Por meio dos resultados apresentados na pesquisa pôde se constatar que o Estágio Supervisionado constitui se um componente curricular obrigatório nos cursos de licenciaturas e desempenha um papel fundamental no processo de formação de professores. O Estágio Supervisionado possibilita a articulação entre a universidade e a sociedade, proporcionando uma integração à realidade escolar e o exercício da futura profissão, bem como e ampliação de conhecimentos e habilidades construídos na universidade e na escola-campo. Neste sentido, o estágio envolve uma atitude de reflexão sobre a teoria e a prática e suas contribuições na formação docente e construção da identidade profissional do licenciado.

Palavras-chave: Estágio Supervisionado, Pedagogia e Formação de professores

\section{ABSTRACT}

This study aimed to analyze the importance of Supervised Internship in the perception of undergraduate students in Pedagogia at the Unimontes. This study presents a qualitative approach, using the questionnaire as an instrument of data collection. Through the results presented by the research, it can be seen that the Supervised Internship is a mandatory curricular component in undergraduate courses and plays a fundamental role in the teacher training process. The Supervised Internship allows the articulation between the university and society, providing integration with the school reality and the exercise of the future profession, as well as the expansion of knowledge and skills built in the university and in the school-field. In this sense, the internship

1 Professora Ma da Universidade Estadual de Montes Claros - Unimontes.

E-mail: meloivanise7@gmail.com

2 Graduanda do Curso de Pedagogia Universidade Estadual de Montes Claros -

Unimontes

3 Professora Dra do Instituto Federal do Norte de Minas Gerais- IFNMG. 
involves an attitude of reflection on theory and practice and their contributions to teacher and the construction of the professional identity of the graduate.

Key words: Supervised Internship, Pedagogy and Teacher Training

\section{INTRODUÇÃO}

A formação de professores para atuarem na educação básica, constitui-se um dos desafios na efetivação das políticas públicas educacionais. A Lei de Diretrizes e Bases da Educação Nacional- Lei $n^{\circ}$ 9394/96 em seu artigo $62^{\circ}$ estabelece que a formação de docentes para atuar na educação básica far-se-á em nível superior, em curso de licenciatura, de graduação plena, em universidades e institutos superiores de educação.

Essa formação deve ser pensada numa perspectiva que possibilite a articulação dos aspectos filosóficos, sociológicos, epistemológicos e didático-metodológicos que permeiam a formação inicial dos docentes e suas propostas pedagógicas devem possibilitar a atualização e qualificação profissional, sendo imprescindível que os cursos contribuíam efetivamente para a melhoria das práticas pedagógicas desenvolvidas pelos professores em sala de aula.

O estágio supervisionado, nos cursos de formação de professores, constitui-se um elemento curricular fundamental para o desenvolvimento dos discentes, possibilitando a articulação entre a universidade e a sociedade, pois é o primeiro contato que o discente tem com seu futuro campo de atuação, propiciando a articulação da teoria e prática adquiridas na universidade e escola campo. Dessa forma, o estágio supervisionado constitui-se em uma atividade de pesquisa, quando os futuros docentes desenvolvem ações e habilidades a partir das situações vivenciadas no ambiente escolar, elaboram projetos que torna possível simultaneamente compreender e problematizar as situações observadas. O estágio possibilita o acadêmico identificar novas e variadas estratégias para solucionar problemas e desenvolver seu raciocínio, autonomia, criatividade, o espírito crítico e reflexivo.

Neste contexto, o objetivo desse estudo foi analisar a importância do estágio supervisionado no curso de licenciatura em Pedagogia, na percepção dos acadêmicos do Curso de Pedagogia na Universidade estadual de Montes Claros- Unimontes. Para tanto, foi realizada uma pesquisa de natureza qualitativa, sendo utilizada como procedimentos a pesquisa bibliográfica e de campo. Tendo como instrumento de coleta de dados o questionário aplicado aos acadêmicos do curso de Pedagogia da Unimontes, lócus desta pesquisa.

\section{A importância do Estágio Supervisionado nos cursos de formação de professores}


O estágio supervisionado constitui-se um componente curricular fundamental na formação docente, pois proporciona ao acadêmico a oportunidades de conhecer a realidade sobre o ambiente de trabalho onde atuará futuramente. De acordo com o Parecer CNE/CP 9/2001 que estabelece as Diretrizes Curriculares Nacionais para a Formação de Professores da Educação Básica, em nível superior, curso de licenciatura, de graduação plena, o estágio curricular supervisionado realizado nas escolas de Educação Básica deve ser vivenciado durante o curso de formação e com tempo suficiente para conhecer sobre as dimensões da atuação profissional, o estágio deve ocorrer a partir da segunda metade do curso, sendo um período de estágio compartilhado onde tenha explícito os objetivos e as tarefas que devem ser realizadas pelas instituições, para que ambos se auxiliem mutuamente e o tempo na escola deve seguir os objetivos de cada momento da formação do estudante.

O espaço onde ocorre o estágio possibilita ao acadêmico uma grande produção de conhecimento, que vai acontecer por meio da articulação dos conteúdos do curso de Pedagogia com as experiências dentro da sala de aula na instituição de ensino, desta maneira é ideal que a proposta do estágio tenha o objetivo de formar um educador que tenha a consciência do seu trabalho, as questões que envolvem o ambiente escolar, o comportamento necessário para estar face a face com os alunos, refletindo criticamente sobre suas ações, vivências, tendo em mente que a sua formação é sempre contínua. Neste sentido, Pimenta \& Lima (2004, p. 43) afirmam que “[...] o estágio possibilita aos futuros profissionais aproximarem-se da escola, ajudando-os a compreender a complexidade das práticas institucionais e das ações aí praticadas por seus profissionais como alternativas no preparo para sua inserção profissional”.

O estágio supervisionado possibilita a articulação entre a universidade e a sociedade, proporcionando uma integração à realidade escolar, e oferecendo maneiras de desenvolvimento e a possibilidade de averiguar na prática toda a teoria adquirida na universidade, oferece amplos benefícios para a aprendizagem e a formação dos acadêmicos. É necessário pensar sobre a questão da teoria e prática nos cursos de formação docente, porque os dois pontos devem estar sempre juntos, complementando entre si, sobre isso Saviani (2006) argumenta que a relação entre teoria e pratica deve ser compreendida como um processo dialético, sendo inseparáveis, um surge em função do outro. A teoria necessita da prática para efetivar o conhecimento transmitido, e a prática necessita da teoria para ter seu fundamento, é necessário os dois para uma formação concreta, porque de certa forma as duas possuem suas especificidades.

A atividade teórica sozinha não gera resultados e, sim, sua relação com a prática, a teoria não é algo que usamos de outros estudos, mas sim como aprender e praticar 
determinada ação (teoriza-se praticando, pratica-se teorizando). A teoria oferece meios de como o estudante poderá investigar seu campo de trabalho, tendo a oportunidade de fazer questionamentos, pensar sobre os problemas encontrados no ambiente escolar e agir nas situações necessárias. Barreiro e Gebran (2006, p. 22) ressaltam que:

A articulação da relação teoria e prática é um processo definidor da qualidade da formação inicial e continuada do professor, como sujeito autônomo na construção de sua profissionalização docente, porque the permite uma permanente investigação e a busca de respostas aos fenômenos e as contradições vivenciadas.

O momento do estágio supervisionado tem que ser interligado com os momentos na sala de aula, com as orientações do professor e com as teorias da área do curso, com os debates e as ideias dos demais colegas, sanando as dúvidas e as dificuldades que surgirem no decorrer do processo. São essenciais inovações sobre a prática de estágio que aproximem de certa maneira as necessidades dos estudantes com a realidade da escola. $\mathrm{O}$ estagiário deve perceber que não há um modelo a ser seguido na sala de aula, e algo que precisa ser construído e elaborado coletivamente.

Os discentes descobrem no tempo de estágio a extensa área que envolve o processo de ensino-aprendizagem, transformando a realidade do acadêmico, muitos anseiam por esse momento, e outros temem o estágio na escola por medo de não estar preparado para ministrar suas aulas, mas o que é necessário frisar, há disciplinas teóricas nos cursos que não ajudam na preparação dos alunos, muitos dos licenciados afirmam que a teoria não representa a prática. O estágio envolve uma atitude de reflexão sobre a teoria e a prática, o trabalho nas escolas e também intervenções, e não se limita apenas dentro de uma sala de aula. .

Além da superação da dicotomia da teoria e prática, o estágio supervisionado contribuirá na construção da identidade profissional do licenciando, os saberes, as experiências auxiliam no processo de construção da identidade de um educador, quando os alunos chegam ao curso de Pedagogia inicialmente eles já conhecem o papel do professor, mas faltam-lhes a consciência identitária. Isso é construído por meio das experiências, durante o período da escola, de professores que marcaram suas vidas, os que deram os bons exemplos e também os que não contribuíram em nada, conhecem as mudanças da história da profissão docente, as dificuldades que os professores enfrentam, como são vistos na sociedade, sua valorização entre diversos aspectos. Sabemos que as experiências que acontecerão desde o início do curso até o final, os conteúdos, os aprendizados ajudam em grande parte na construção da nossa identidade profissional, os cursos de formação do professor devem desenvolver nos discentes, habilidades, conhecimentos, valores e atitudes que permitirão que 
de pouco a pouco, com os desafios presentes ao longo desse processo possam ir construindo sua identidade, e possibilitando situações que todos os alunos possam investigara atividade docente.

O estágio supervisionado fortalece a construção da identidade do professor, a partir da história de cada um, de experiências, na didática e na prática de ensino, mostra também as características e modos ideais para exercer uma determinada profissão, levando a perceber as condições e requisitos necessários. No momento do estágio, o indivíduo será preparado para assumir a profissão que escolheu futuramente no decorrer desse período e inevitável que o estagiário se encontre muitas das vezes em situações de cansaço, de dificuldades encontradas na área de educação, por problemas sociais e todos esses aspectos contribuem para sua formação identitária.

Dessas dificuldades que surgiram precisamos refletir criticamente, tomando decisões que solucionarão os problemas. Outro aspecto que o discente aprenderá será a utilização dos recursos teóricos e metodológicos no exercício da sua profissão, Pimenta (1999, p. 45) afirma:

Uma identidade profissional se constrói, pois a partir da significação social da profissão, da revisão constante dos significados sociais da profissão, da revisão das tradições. Mas também da reafirmação de práticas consagradas culturalmente e que permanecem significativas. Praticas que resistem a inovações porque prenhes de saberes validos as necessidades da realidade. Do confronto entre as teorias e as práticas, da construção de novas teorias. Constrói-se, também pelo significado que cada professor, enquanto ator e autor, confere a atividade docente em seu cotidiano a partir de seus valores, de seu modo de situar-se no mundo, de sua história de vida, de suas representações, de seus saberes, de suas angustias e anseios, do sentido que tem em sua vida o ser professor. Assim como a partir de sua rede de relações com outros professores, nas escolas, nos sindicatos e em agrupamentos.

De certa forma, tudo o que o acadêmico aprender durante o curso, os estágios e as demais atividades ajudarão na construção da identidade profissional, o estágio efetiva o processo de ensino-aprendizagem para a formação do licenciado. O Parecer 21 de 2001 que dispõe sobre a duração e carga horária dos cursos de Formação de Professores da Educação Básica, em nível superior, curso de licenciatura, de graduação plena, do Conselho Nacional de Educação define que o estágio é:

Como um tempo de aprendizagem que, através de um período de permanência, alguém se demora em algum lugar ou ofício para aprender a pratica do mesmo e depois poder exercer uma profissão ou ofício. Assim o estágio supõe uma relação pedagógica entre alguém que já é um profissional reconhecido em um ambiente institucional de trabalho e um aluno estagiário [...] é o momento de efetivar um processo de ensino/aprendizagem deste estagiário. 
É importante ressaltar na relação professor e estagiário deve haver reciprocidade entre ambos, o professor regente da turma deve compartilhar com o estagiário a forma como trabalha, dar orientações e sugestões que possam ajudar no aprendizado do acadêmico para que ele possa assim desempenhar uma tarefa com mais segurança. A profissão docente deve ser pensada diariamente por quem a exerce, para que evolução, solidariedade coletiva, orientando o estagiário sobre o trabalho do educador e sua realidade.

\section{A Importância do Estágio Supervisionado na perspectiva dos acadêmicos do curso de Pedagogia}

O estágio supervisionado como fonte de pesquisas permite que os discentes por meio da investigação conheçam e desenvolvam posturas para ser um bom educador, esclarece à compreensão das várias facetas da área educacional. A pesquisa visa articular a teoria e a prática e favorece uma reflexão e ação, tornando o educador mais autônomo em sua profissão. Neste sentido, foi realizado este estudo com o objetivo de analisar as percepções dos acadêmicos quanto à importância do estágio supervisionado no curso de Pedagogia da Unimontes. Para tanto, foi utilizado um questionário, no qual os acadêmicos do $6^{\circ}$ período de Pedagogia registraram as suas perspectivas sobre o estágio supervisionado e sua importância na formação docente. Os dados obtidos foram analisados com base no referencial teórico que fundamentou este estudo, em uma abordagem de pesquisa qualitativa.

A primeira pergunta teve como objetivo conhecer a concepção dos acadêmicos sobre o Estágio Curricular Supervisionado, que evidencia em primeiro momento, o foco desta pesquisa. Para os acadêmicos o estágio supervisionado é indispensável para a formação docente, pois proporciona aos estudantes o contato direto com o ambiente escolar, fazendo-os compreender como é o funcionamento da instituição, a sua verdadeira realidade, mostrando as dificuldades que os educadores encontram no campo de trabalho e possibilita a articulação da teoria e prática abordadas em sala de aula. Os acadêmicos, nesta primeira, pergunta abordaram a relação teoria e prática que intercala o que aprenderam dentro da universidade com a experiência vivenciada durante o estágio

O estágio supervisionado deve oferecer aos discentes um momento de conhecimento sobre o trabalho na educação e, não, para ensinar um modelo cristalizado de ministrar aulas a partir das observações feitas pelo estagiário. É ideal compreender também que as condições físicas da escola interferem no processo de aprendizagem dos alunos, muitas vezes a falta de recursos torna tudo mais trabalhoso e não depende apenas do professor. Desta maneira Pimenta (2001, p. 13) aborda que: 
O estágio terá por finalidade propiciar ao aluno uma aproximação a realidade na qual irá atuar. Portanto, não se deve colocar o estágio como "polo prático" do curso, mas como uma aproximação á pratica em que será consequentemente a teoria estudada no curso, que por sua vez, deverá se construir numa reflexão sobre e a partir da realidade da escola pública.

É necessário que o estagiário reflita sobre a realidade e a complexidade da sua área de trabalho, porque esse momento será decisivo para ele. Nesta perspectiva o estagiário compreende as relações que configuram o ambiente escolar, embora o tempo as vezes não é suficiente, mas ainda sim efetiva no indivíduo um conhecimento que ele produzirá na escola, no decorrer desse tempo o aluno também deve analisar o contexto da comunidade onde a escola está inserida, as concepções dos educadores, as metas planejadas e passar a se informar sobre as políticas educacionais, pois todos esses aspectos estão diretamente ligados à aprendizagem dos alunos.

Sobre isso, Pimenta e Lima (2004, p. 12) afirmavam que "o estágio é uma atividade teórico e prática de conhecimento, fundamentação, diálogo e intervenção na realidade, é no contexto escolar da sala de aula, da escola, do sistema de ensino e da sociedade que a práxis se dá", então é necessária uma verdadeira intervenção para ocorrer de fato a consolidação da aprendizagem na prática.

Quando questionados sobre a importância do estágio supervisionado para a formação docente, os acadêmicos afirmaram que o estágio supervisionado é extremamente importante, favorecendo o aperfeiçoamento do que aprenderam no conteúdo ministrado em sala de aula. Entender qual é o papel do estágio na formação docente, seria abrir um leque de oportunidades e conhecimentos para os estagiários, além de fortalecer o vínculo entre a escola e a universidade, no estágio o estudante vai lidar com determinadas situações que acontecem quando estão na escola, que serve para concretizar o aprendizado.

O estágio supervisionado proporcionará ao futuro docente uma integração do que ele sabe, ou seja, do que foi aprendido na faculdade, e como ele atuará, quais metodologias ele utilizará, certamente, cada um tem o jeito de trabalhar, de ensinar, cada pessoa utiliza na prática o que ele acha relevante do que aprendeu o que absorveu das diversas aulas ministradas. Evidentemente, todos os acadêmicos abordaram novamente a relação teoria e prática no estágio supervisionado, enfatizando a unidade dos dois termos.

É importante frisar que o estágio também oferece outros conhecimentos, não sendo apenas o de planejar e ministrar aulas, sendo também como campo de pesquisa para o docente onde ele esteja constantemente buscando mais conhecimentos sobre sua área de trabalho, para que não se acomode a rotina da escola. Dando ênfase à importância do estágio 
supervisionado para a formação do professor, é importante ressaltar que ele possibilita o conhecimento sobre questões políticas, críticas e sociais que englobam a instituição escolar.

Quanto a carga horária do estágio supervisionado, a maioria dos acadêmicos considera a carga horária adequada. No entanto, alguns acadêmicos ressaltam que o fator que mais que dificulta o estágio supervisionado são os trabalhos acadêmicos realizados concomitantemente nas demais disciplinas do curso. Desta maneira, a carga horária se torna exaustiva, porque além de lidar com os compromissos do estágio, o acadêmico ainda precisar conciliar com os trabalhos da universidade. Outro ponto que acontece é que em muitos casos os acadêmicos exercem alguma atividade profissional para seu próprio sustento e no período de estágio na escola, a partir do $5^{\circ}$ período do curso, surgem as dificuldades para conciliar o tempo de trabalho com o tempo de estudos e estágio supervisionado.

Quando questionados se o estágio supervisionado estabelece relações com as outras disciplinas do curso, os acadêmicos afirmaram que o estágio tem relação com algumas disciplinas como as disciplinas de Psicologia, Didática e as Metodologias que estão em afinidade e cooperam na realização do estágio supervisionado na escola campo. Alguns acadêmicos consideraram que muitas vezes há um distanciamento entre as teorias abordadas nas disciplinas do curso e a prática vivenciada nas escolas, apontando que "na prática a teoria é outra”. Neste momento, fica explícito que a articulação da teoria e prática está distanciada, o conhecimento adquirido durante o curso difere-se, na maioria das vezes, da realidade escolar, embora percebendo que nas perguntas anteriores a maioria dos acadêmicos respondeu que o estágio possibilita a articulação entre prática a teoria do curso. Os acadêmicos de certa forma estabelecem alguns vínculos com as teorias e utilizam no estágio supervisionado.

O estágio não deve ser concebido como parte prática do curso, pois precisa estar articulado aos conteúdos abordados na universidade e na sala de aula na escola, um complementa o outro, ambos dependem um do outro para se concretizarem. Pimenta e Lima (2004, p. 44) ressaltam que o estágio deve ser o eixo de todas as disciplinas do curso:

Isso se pode ser conseguido se o estágio for uma preocupação, um eixo de todas as disciplinas do curso, e não apenas erroneamente denominadas "praticas". Todas as disciplinas, conforme nosso entendimento é ao mesmo tempo "teorias e prática". Num curso de formação de professores, todas as disciplinas, as de fundamentos e as didáticas, devem contribuir para sua finalidade, que é formar professores a partir da análise, da crítica e da proposição de novas maneiras de fazer educação. Todas as disciplinas necessárias necessitam oferecer conhecimentos e métodos para esse processo.

Com relação às principais dificuldades encontradas pelos acadêmicos durante o estágio, destacam-se as a indisciplina dos alunos na sala, o planejamento das aulas, os 
métodos tradicionais utilizados por alguns professores, a burocracia dos documentos comprobatórios de estágio na universidade e o fato de não conseguirem conciliar o tempo de serviço, família e estudos. Quanto aos pontos positivos do estágio os acadêmicos destacaram à aprendizagem construída, preparação para atuar futuramente na profissão, recepção do estagiário nas escolas, o carinho dos alunos e destacaram as atividades lúdicas realizadas pelos professores regentes em algumas aulas.

O estágio supervisionado propicia experiências significativas aos acadêmicos, visando a articulação da teoria e prática e constitui-se um momento para que possam analisar suas escolhas sobre sua profissão. É a partir do estágio supervisionado que os acadêmicos vão tomar a decisão de trabalhar ou não na área da Educação, dessa forma cursos de formação de professores devem possibilitar aos futuros profissionais o acesso aos instrumentos necessários para a efetiva participação no desenvolvimento social, político e econômico do país.

\section{Considerações finais}

O estágio supervisionado tem um papel fundamental na formação docente, pois oferece várias oportunidades de construção de atitude de pesquisa e construção do conhecimento aos acadêmicos, ampliando as habilidades e acima de tudo refletindo sobre todos os aspectos da futura área de trabalho, além de proporcionar uma convergência entre o saber teórico e a prática na escola-campo. A partir do momento do estágio os futuros professores percebem a complexidade dentro das instituições escolares, tendo que passar por situações que ajudam na inserção profissional no ambiente escolar.

Diante deste estudo foi possível constatar a importância do estágio supervisionado na formação dos acadêmicos do curso de Pedagogia, sendo o estágio indispensável numa formação de qualidade, tendo em vista que um bom educador não se constitui apenas com conteúdos teóricos e não só na prática, e preciso que haja uma reflexão e ação, e que seja buscado a consolidação de novos saberes no decorrer da profissão.

No entanto, também foi possível constatar as dificuldades enfrentadas pelos acadêmicos na realização do estágio supervisionado na escola campo. Essas situações dizem respeito às dificuldades existentes na complexidade da realidade nas instituições de ensino, o excesso de burocracia no preenchimento dos documentos comprobatórios do estágio supervisionado na universidade, os trabalhos acadêmicos realizados nas demais disciplinas do curso de Pedagogia e a falta de conciliação entre trabalho, família e estudos. 
O estágio supervisionado contribui de forma significativa nos cursos de formação de professores nas universidades, constituindo - se um elemento imprescindível na superação da dicotomia teoria e prática e na construção da identidade profissional

\section{Referências}

BARREIRO, Iraide Marques de Freitas; GEBRAN, Raimunda Abou. Prática de Ensino e Estágio Supervisionado na formação de Professores. São Paulo: Avercamp, 2006.

BRASIL. MEC. Lei no . 9.394, de 20 de dezembro de 1996. Estabelece as Diretrizes e Bases da Educação Nacional. Diário Oficial da União. Brasília, v. 134, n. 1.248, p. 27.833-27.841, 23 dez. Disponível em:< http://www.planalto.gov.br/ccivil_03/Leis/L9394.htm>. Acesso em: 15 jun. 2019

BRASIL. Conselho Nacional de Educação. Parecer CNE/CP no 09/2001. Diretrizes Curriculares Nacionais para a Formação de Professores da Educação Básica, em nível superior, curso de licenciatura, de graduação plena. Disponível em. Acesso em: :< http://www.planalto.gov.br/cne/pdf/027.pdf>. Acesso em: 15/04/2019.

BRASIL. Conselho Nacional de Educação. Parecer no 21 /2001. Dispõe sobre a duração e carga horária dos cursos de Formação de Professores da Educação Básica, em nível superior, curso de licenciatura, de graduação plena. Disponível em: <http://www.planalto.gov.br/ccivil_03/Leis/L9394.htm>. Acesso em: 15 jun. 2019.

PIMENTA, Selma Garrido (org.). Formação de professores: identidade e saberes da docência. In: PIMENTA, Selma Garrido. O Estágio na Formação de Professores: unidade teoria e prática? 4. ed. São Paulo: Cortez, 2001.

PIMENTA, Selma Garrido; LIMA, Maria Socorro. Estágio e docência. São Paulo: Cortez, 2004.

PIMENTA,S.G.(Org). Saberes pedagógicos e atividade docente. São Paulo: Cortez, 1999.

SAVIANI, Dermeval O Legado Educacional do Século XX no Brasil. Campinas-SP: Autores Associados, 2004

Artigo recebido em: 19/02/2020. Artigo aceito em: 09/03/2020. 